\title{
Nível de Proteína Bruta para Bezerros de Corte Desmamados aos 66 Dias de Idade
}

\author{
Leonir Luiz Pascoal ${ }^{1}$, Eduardo da Costa Eifert ${ }^{2}$, João Restle ${ }^{3}$
}

\begin{abstract}
RESUMO - O objetivo deste trabalho foi avaliar o consumo médio diário de matéria seca (CMS), CMS por $100 \mathrm{~kg}$ de peso vivo (CMSP), CMS por unidade de peso metabólico (CMSM), a conversão alimentar (CA) e o ganho de peso médio diário (GMD) de bezerros de corte, alimentados com diferentes níveis de proteína bruta (PB) na dieta. Foram utilizados 47 bezerros inteiros, da raça Braford, desmamados aos 66 dias de idade com peso médio de 76,4 kg. Os animais foram alimentados à vontade com silagem de aveia e concentrado (50/50), com níveis de 13,15, 17 e 19\% de PB na dieta total. O período de adaptação ao alimento e manejo foi de 21 dias. Os animais foram pesados com jejum de sólidos de 14 horas, a intervalos regulares de 21 dias durante o período experimental de 84 dias. Verificou-se, por meio da análise de regressão linear e múltipla, que não ocorreram efeitos significativos relacionando o CMS, CMSP, CMSM, CA e GMD e o nível de PB na dieta. Observou-se que CMS, CMSP e CMSM aumentaram linearmente com o avanço do período experimental, demonstrando o aumento da capacidade de ingestão com o aumento do peso vivo. Os valores de GMD obtidos foram de 644; 701; 693 e $730 \mathrm{~g} /$ dia para os níveis de 13; 15; 17 e 19\% de PB na dieta, respectivamente. Os ganhos de peso foram superiores àqueles normalmente atingidos ao pé da vaca em condições de campo nativo ou desmamados precocemente e mantidos em pastagem cultivada.
\end{abstract}

Palavras-chave: Braford, consumo, crescimento, desmame precoce, ganho de peso, nível de proteína, silagem de aveia

\section{Level of Crude Protein for Beef Calves Weaned at 66 Days of Age}

\begin{abstract}
The objective of this work was to evaluate the average daily dry matter intake (DMI), DMI per $100 \mathrm{~kg}$ of live weight (DMIP), DMI per unit of metabolic weight (DMIM), feed: gain (FG) and average daily weight gain (ADG) of beef calves fed with different levels of crude protein in the diet. Forty-seven Braford intact male calves, 66 days old and $76.4 \mathrm{~kg}$ of live weight were used. Animals were full fed with oat silage and concentrate (50/50), with 13;15;17 and 19\% of CP in diet. The adaptation period to the feed and handling was 21 days. The calves were weighted after a fasting period of 14 hours, in regular intervals of 21 days across the experimental period of 84 days. Data were submitted to regression analysis. No significant relation was detected between DMI, DMIP, DMIM, FC, and ADG with the level of crude protein in the diet. The DMI, DMIP and DMIM linearly increased as the experimental period advanced, indicating the increase of the ingestion capacity with the increase of live weight. The values for ADG obtained were 644; 701; 693 and $730 \mathrm{~g} /$ day, for the 13; 15; 17 and 19\% of CP levels, respectively. The obtained ADG were higher than to those normally obtained by calves suckling their dams and kept on native pasture or early weaned and kept on cultivated pasture.
\end{abstract}

Key Words: Braford, feed intake, growth, early weaning, weight gain, protein level, oat silage

\section{Introdução}

A pecuária de corte brasileira apresenta índices de produtividade baixos, quando comparados aos de países mais desenvolvidos. Aumentar os índices de produtividade é necessário para melhorar a rentabilidade e permanência do pecuarista na atividade. No que se refere à reprodução em bovinocultura de corte, várias técnicas têm sido estudadas, sendo o desmame precoce (60-90 dias) uma prática que permite elevar a taxa de natalidade com relativa facilidade, a custo compatível e com boa aceitação por parte do produtor (PASCOAL et al., 1996).

A prática do desmame precoce permite o direcionamento dos nutrientes da produção de leite para atender às exigências reprodutivas (LUSBY et al., 1981). Vacas que foram desterneiradas precocemente, em relação às do desmame tradicional (sete meses), apresentaram maior ganho de peso no período de serviço, maior taxa de prenhez e menor intervalo do parto à iniciação da atividade ovariana (LUSBY et al., 1981; NEVILLE JR. et al., 1981; e RESTLE et al., 1992), apresentando maior eficiência alimentar, quando avaliada somente a vaca ou o conjunto formado pelo bezerro e vaca (PETERSON et al., 1987).

Segundo RESTLE e VAZ (1998), o desmame precoce pode prejudicar o adequado desenvolvimento do bezerro. Vários pesquisadores apontam correla- 
ção acima de 0,56 entre a produção de leite da vaca e o ganho de peso dos bezerros. No entanto, a produção de leite declina com o avanço da idade do bezerro, sendo que a partir dos 90 a 120 dias de idade a correlação entre leite e ganho de peso é baixa (RUTLEDGE et al., 1971; ROBISON et al., 1978).

ROBISON et al. (1978) observaram que o leite supriu as necessidades para manutenção e crescimento no primeiro mês, porém, a partir do quarto mês de vida do bezerro, o aporte de leite não atendeu às necessidades de manutenção. De acordo com BOGGS et al. (1980), a partir dos 60 dias de idade, o bezerro passa a consumir mais forragem para complementar a dieta e atender às necessidades de nutrientes para ganho de peso. Observaram ainda que, durante esta fase, para cada $\mathrm{kg}$ de matéria seca de forragem consumida, houve acréscimo de $0,2 \mathrm{~kg}$ no ganho de peso diário dos bezerros. Dessa maneira, LUSBY et al. (1981) citam que os bezerros podem ser desmamados com seis a oito semanas, obtendo pesos aceitáveis aos 210 dias de idade.

Existem vários trabalhos publicados no país a respeito da nutrição e do desempenho de bezerros desmamados precocemente. No entanto, quase todos se referem ao desmame de raças leiteiras, com manejo, alimentos e, principalmente, idades diferentes daquelas pretendidas para bovinos de corte. Vários trabalhos são encontrados na literatura estrangeira relacionando o desmame precoce (60-90 dias) com os níveis protéicos na dieta (THOMAS et al., 1976; NEVILLE JR et al., 1977; e VEIRA et al., 1980). No entanto, os níveis energéticos utilizados nestes trabalhos são muito acima daqueles utilizados em nosso meio.

De maneira geral, técnicos e extensionistas têm recomendado dietas com elevados níveis de proteína na dieta de bezerros de corte desmamados precocemente. Estas recomendações são feitas empiricamente sem embasamento científico.

Dessa forma, o presente trabalho teve como objetivo avaliar as respostas no consumo de matéria seca, no ganho de peso e na conversão alimentar de bezerros de corte desmamados aos 66 dias de idade, quando alimentados com diferentes níveis de proteína bruta na dieta.

\section{Material e Métodos}

O experimento foi conduzido no Departamento de Zootecnia da Universidade Federal de Santa Maria, no período de dezembro de 1996 a abril de 1997. Foram utilizados 48 bezerros inteiros, da raça Braford (5/8 Hereford 3/8 Nelore), distribuídos nos seguintes tratamentos: T13 = dieta com 13\% PB (proteína bruta) na matéria seca $(\mathrm{MS}) ; \mathrm{T} 15$ = dieta com $15 \% \mathrm{~PB}$; $\mathrm{T} 17$ = dieta com 17\% PB; T19 = dieta com 19\% PB.

Todos os animais utilizados no trabalho proviam da Estância Guatambu (Don Pedrito, RS), sendo todos filhos de vacas primíparas parindo aos 24 meses de idade e nascidos entre os dias 09 e 29/10/96, com idade média à desmama de 66 dias e peso médio de 76,4 kg. Os animais foram alojados em 16 piquetes com $40 \mathrm{~m}^{2}$ de área, providos de bebedouro regulado por bóia automática e cocho de madeira com disponibilidade de $0,70 \mathrm{~m}$ para cada bezerro.

A dieta foi constituída de silagem de aveia, colhida em estádio de grão leitoso (apresentando 26,6\% de MS), e de concentrado, perfazendo a relação volumoso:concentrado de 50/50, base matéria seca. O concentrado era constituído de farelo de soja (48\% $\mathrm{PB}$ ), grão de sorgo triturado, sal comum, calcário calcítico, fosfato bicálcico e ionóforo. Os resultados das análises bromatológicas dos ingredientes que compunham o concentrado estão presentes na Tabela 1. A alimentação era fornecida, em partes iguais, duas vezes ao dia, sendo as sobras retiradas do cocho e pesadas antes da alimentação no período da manhã.

A fase de adaptação ao manejo e à alimentação teve duração de 21 dias, desde o desmame até o início do experimento, quando os animais receberam concentrado (1\% PV com 24\% PB) mais volumoso. Para controle da evolução do peso, foram realizadas pesagens periódicas de 21 dias, com jejum prévio de sólidos de 14 horas nos 84 dias do período experimental.

Foram avaliados os consumos médios diários de matéria seca (CMS), CMS/100 kg de PV (CMSP),

Tabela 1 - Resultados das análises dos ingredientes usados nas dietas

Table 1 - Results of the analysis of ingredients used in the diets

\begin{tabular}{lccc}
\hline & $\begin{array}{c}\text { DIVMO }(\%) \\
\text { IVOMD }\end{array}$ & $\begin{array}{c}\text { Proteína bruta(\%) } \\
\text { Crude protein }\end{array}$ & $\begin{array}{c}\text { FDN }(\%) \\
\text { NDF }\end{array}$ \\
\hline $\begin{array}{l}\text { Farelo de soja } \\
\text { Soybean meal }\end{array}$ & 90,90 & 45,92 & $7,79^{1}$ \\
$\begin{array}{l}\text { Sorgo triturado } \\
\text { Ground sorghum }\end{array}$ & 82,30 & 8,40 & $13,31^{1}$ \\
$\begin{array}{l}\text { Silagem de aveia } \\
\text { Oat silage }\end{array}$ & 54,30 & 7,10 & 71,85 \\
\hline
\end{tabular}

DIVMO - digestibilidade in vitro da matéria orgânica (\%).

1 Valores extraídos do NRC (1984).

IVMOD - in vitro organic matter disappearance (\%).

1 Values obtained from NRC (1984). 
Rev. bras. zootec.

CMS por unidade de peso metabólico (CMSM), consumo de FDN diário (CFDN), CFDN por $100 \mathrm{~kg}$ de PV (CFDNP), conversão alimentar (CA) e ganho de peso médio diário (GMD).

O delineamento experimental foi o inteiramente casualizado, com quatro tratamentos e quatro repetições, sendo cada repetição formada por um lote de três bezerros. Foi retirado um bezerro do tratamento $\mathrm{T} 17 \% \mathrm{~PB}$, por motivo de traumatismo, ainda no primeiro período de avaliação. Os resultados obtidos foram submetidos à análise de variância e teste ' $t$ ' e regressão linear e múltipla, com o auxílio do programa estatístico SAS System (SAS, 1990).

\section{Resultados e Discussão}

Os dados referentes às médias e às equações de regressão para CMS, CMSP, CMSM, CFDN, CFDNP, GMD, CA, peso médio inicial (PI) e peso médio ao final do experimento (PF) estão presentes nas Tabelas 2 e 3, respectivamente.

Não foram observados efeitos significativos dos níveis de proteína bruta nas diferentes formas de expressar o consumo de matéria seca (CMS, CMSP e CMSM) e o consumo de FDN (CFDN e CFDNP). Pode-se observar, na Tabela 2, que a variação de 13 a 19\% de PB na dieta propiciou consumos de matéria seca bastante similares entre os tratamentos, quando expressos tanto em percentual do peso vivo (média de 2,53 kg MS) como por unidade de peso metabólico (média de 82,73 g). Vários autores citam que o nível de PB na dieta pode influenciar o consumo (OWENS e GOETSCH, 1993; VALADARES et al., 1997). Segundo OWENS e GOETSCH (1993), níveis baixos de nitrogênio no rúmen podem limitar o consumo de matéria seca, pela redução do crescimento microbiano, e, conseqüentemente, a taxa de desaparecimento do alimento. VALADARES et al. (1997), ao avaliarem o consumo de matéria seca de novilhos zebu alimentados com níveis crescentes de 7 a 14,5\% de PB na dieta, observaram menor CMS para o tratamento com $7 \%$ PB em relação àqueles com maior concentração protéica $(9,5 ; 12$; e $14,5 \% \mathrm{~PB})$. No entanto, não verificaram diferenças significativas no consumo

Tabela 2 - Médias do consumo médio diário de matéria seca (CMS), por $100 \mathrm{~kg}$ de peso vivo (CMSP) e tamanho metabólico (CMSM), consumo médio diário de FDN (CFDN), por $100 \mathrm{~kg}$ de peso vivo (CFDNP), ganho de peso médio diário (GMD), conversão alimentar (CA), pesos inicial e final, de bezerros de corte alimentados com diferentes níveis de proteína

Table 2 - Means for average daily dry matter intake (DMI), per $100 \mathrm{~kg}$ of live weight (DMIP) and metabolic weight (DMIM), daily NDF intake (NDFI), per $100 \mathrm{~kg}$ of live weight (NDFIP), average daily gain (ADG), feed: gain ratio (FG), initial and final weight, of beef calves fed different protein levels

\begin{tabular}{|c|c|c|c|c|c|}
\hline & \multicolumn{4}{|c|}{$\begin{array}{c}\text { Tratamento } \\
\text { Treatment }\end{array}$} & \multirow[t]{2}{*}{$\begin{array}{c}\text { Desvio-padrão } \\
\text { Standard deviation }\end{array}$} \\
\hline & $\mathrm{T} 13$ & $\mathrm{~T} 15$ & $\mathrm{~T} 17$ & T19 & \\
\hline $\begin{array}{l}\mathrm{CMS}, \mathrm{kg} \text { /animal } \\
\text { DMI, kg/animal }\end{array}$ & 2,86 & 2,95 & 2,83 & 2,90 & $\pm 0,0888$ \\
\hline $\begin{array}{l}\mathrm{CMSP}, \mathrm{kg} \\
D M I P, \mathrm{~kg}\end{array}$ & 2,56 & 2,53 & 2,54 & 2,50 & $\pm 0,0527$ \\
\hline $\begin{array}{l}\text { CMSM, g/PV } \\
D M I M, g / L W^{0,75}\end{array}$ & 83,19 & 83,25 & 82,55 & 81,94 & $\pm 1,7476$ \\
\hline $\begin{array}{l}\text { CFDN, } \mathrm{kg} \\
N D F I, \mathrm{~kg}\end{array}$ & 1,189 & 1,122 & 1,112 & 1,180 & $\pm 0,0342$ \\
\hline $\begin{array}{l}\text { CFDNP, } \mathrm{kg} \\
N D F I P, \mathrm{~kg}\end{array}$ & 1,047 & 1,044 & 1,027 & 1,010 & $\pm 0,0097$ \\
\hline $\begin{array}{l}\mathrm{GMD}, \mathrm{kg} / \mathrm{dia} \\
A D G, \mathrm{~kg} / \text { day }\end{array}$ & 0,644 & 0,701 & 0,693 & 0,730 & $\pm 0,0380$ \\
\hline $\begin{array}{l}\mathrm{CA} \\
F G\end{array}$ & 4,51 & 4,22 & 4,11 & 3,98 & $\pm 0,1860$ \\
\hline $\begin{array}{l}\text { Peso inicial, } \mathrm{kg} \\
\text { Initial weight, } \mathrm{kg}\end{array}$ & 84,8 & 87,1 & 82,3 & 85,5 & $\pm 5,093$ \\
\hline $\begin{array}{l}\text { Peso final, } \mathrm{kg} \\
\text { Final weight, } \mathrm{kg}\end{array}$ & 138,8 & 146,0 & 140,5 & 146,8 & $\pm 8,318$ \\
\hline
\end{tabular}

$P>0,05$ ( $P>05)$. 
Tabela 3 - Equação de regressão, coeficiente de determinação $\left(R^{2}\right)$ e coeficiente de variação (CV) para o consumo médio diário de matéria seca $\mathrm{kg}(\mathrm{CMS})$, por $100 \mathrm{~kg}$ de peso vivo (CMSP) e tamanho metabólico em g/kg0,75 (CMSM), consumo médio diário de FDN em $\mathrm{kg}$ (CFDN), por $100 \mathrm{~kg}$ de peso vivo (CFDNP), ganho de peso médio diário em kg (GMD) e conversão alimentar (CA) de bezerros de corte alimentados com diferentes níveis de proteína na dieta

Table 3 - Regression equation, coefficient of determination $\left(R^{2}\right)$ and coefficient of variation (CV) for average daily dry matter intake in $\mathrm{kg}$ (DMI), per $100 \mathrm{~kg}$ of live weight (DMIP) and metabolic weight in $\mathrm{g} / \mathrm{kg}{ }^{75}$ (DMIM), for daily NDF intake in $\mathrm{kg}$ (NDFI), per 100 $\mathrm{kg}$ live weight (NDFIP), average daily gain in $\mathrm{kg}(A D G)$ and feed:gain ratio $(F / G)$ of beef calves fed different protein level in the diet

\begin{tabular}{|c|c|c|c|}
\hline $\begin{array}{l}\text { Equação de regressão } \\
\text { Regression equation }\end{array}$ & $\mathrm{P}>\mathrm{F}$ & $\mathrm{R}^{2}$ & CV\% \\
\hline $\begin{array}{l}\mathrm{CMS}=-31,9159+6,6476 \mathrm{NP}-0,4186 \mathrm{NP}^{2}+0,0087 \mathrm{NP}^{3} \\
D M I\end{array}$ & 0,3141 & 8,54 & 6,15 \\
\hline $\begin{array}{l}\text { CMSP }=2,6751-0,0089 \mathrm{NP} \\
D M I P\end{array}$ & 0,4321 & 4,47 & 3,88 \\
\hline $\begin{array}{l}\text { CMSM=-86,30-0,23NP } \\
D M I M\end{array}$ & 0,5489 & 2,62 & 3,92 \\
\hline $\begin{array}{l}\text { CFDN }=-23,9933+4,8745 \mathrm{NP}-0,3107 \mathrm{np}^{2}+0,0065 \mathrm{np}^{3} \\
\text { NDFI }\end{array}$ & 0,0633 & 30,39 & 5,82 \\
\hline $\begin{array}{l}\text { CFDNP }=1,1548-0,0068 \mathrm{np} \\
\text { NDFIP }\end{array}$ & 0,1560 & 13,84 & 3,86 \\
\hline $\begin{array}{l}\mathrm{GMD}=0,4914+0,0126 \mathrm{NP} \\
A D G\end{array}$ & 0,1369 & 15,10 & 10,27 \\
\hline $\begin{array}{l}\mathrm{CA}=5,5826-0,0861 \mathrm{NP} \\
F G\end{array}$ & 0,0558 & 23,70 & 8,79 \\
\hline
\end{tabular}

de matéria seca entre os níveis 9,5 e 14,5\% PB, assim como não detectaram regressão significativa para consumo de matéria seca frente aos níveis de proteína testados.

Respostas quadráticas no consumo de MS com o nível de proteína foram observadas por NEVILLE JR. et al. (1977) em dietas contendo 87/13 de relação concentrado/volumoso, associadas aos níveis de 14,5; 18,9; 23,7; e 28,5\% de PB na alimentação de bezerros Angus e Hereford, desmamados com idade média de 48 dias. Os autores observaram que o ganho de peso diário esteve positivamente relacionado com a idade a qual o bezerro foi desmamado. Distribuição quadrática no consumo de MS, com o aumento do nível protéico da dieta, também foi observada por VEIRA et al. (1980), em bezerros de raças leiteiras desmamados com 8 a 12 semanas de idade, utilizando níveis de 9,9 a $16,2 \%$ de PB em dietas com $92,5 \%$ de concentrado.

Da mesma forma que para CMS, o consumo de FDN (CFDN e CFDNP) não foi influenciado pelos níveis de $\mathrm{PB}$ na dieta $(\mathrm{P}>0,05$; Tabelas 2 e 3). A estimativa do CMS pelo consumo de FDN torna-se importante, pois FDN representa a porção da dieta que ocupa maior volume. Segundo MERTENS (1992), para dietas com baixa densidade energética, a ingestão de alimentos é regulada pela capacidade de distensão ruminal, sendo descrita por VAN SOEST (1994) como a "Teoria do Hotel", que também representa a porção de menor degradação da dieta (JUNG e ALLEN, 1995). A média de CFDNP neste trabalho foi de $1,032 \mathrm{~kg}$ de FDN, valor pouco inferior aos encontrados por RESENDE et al. (1995), em novilhos Nelore, Holandês e Búfalos (média de 1,25 kg CFDNP), e próximo dos níveis de 1,1 a 1,2 $\mathrm{kg}$ de CFDNP recomendados para vacas lactantes por MERTENS (1992). No entanto, deve ser observado que as médias de CFDNP encontradas neste trabalho são oriundas de bezerros recém desmamados, os quais têm a necessidade de desenvolver o rúmen, aumentando sua capacidade de ingestão, para que alcancem consumos máximos.

O aumento do nível de $\mathrm{PB}$, de 13 para $19 \%$ na dieta, permitiu ganho de peso médio de $0,692 \mathrm{~kg} / \mathrm{dia}$. Ao se analisarem os dados por regressão linear e múltipla, observou-se comportamento linear na dispersão dos resultados, apesar de não-significativo $(\mathrm{P}=0,1369)$, possivelmente pela proximidade entre os 
Rev. bras. zootec.

níveis protéicos utilizados.

Ao avaliar o desempenho de bezerros desmamados dos 41 dias até os 102 dias, com dietas contendo 10 a $17 \%$ de PB, THOMAS et al. (1976) constataram menores ganhos diários para dietas com $10 \%$ de PB e maiores para dietas com 12 a $17 \%$ de PB, sem observar diferenças significativas entre estes últimos níveis (média de $850 \mathrm{~g} / \mathrm{dia}$ ). NEVILLE JR. et al. (1977) relatam ganhos diários médios de $981 \mathrm{~g} /$ dia de bezerros desmamados aos 48 dias e alimentados com níveis de 14,5 a $28,5 \%$ de $\mathrm{PB}$, citando que os melhores ganhos foram aqueles em dietas com 18,9 e $23,7 \%$ de PB.

Ganhos de peso mais próximos aos verificados no presente trabalho foram obtidos por JAHN et al. (1976), que observaram interação entre o nível de PB $(9,0 ; 11,5 ; 14,5 ;$ e $17,5 \%)$ e a concentração de FDA $(11,18$ e $25 \%)$ da dieta. Esses autores observaram maiores respostas ao nível de proteína em dietas contendo $11 \%$ de FDA que naquelas contendo $25 \%$, com GMD de 0,97 e 0,76 kg/dia, respectivamente. Sabe-se, no entanto, que FDA está relacionada de forma inversa à digestibilidade dos alimentos e, conseqüentemente, ao valor energético.

As diferenças nos GMD observadas na literatura, possivelmente estão relacionados ao nível energético das dietas e às taxas de degradação da proteína e dos carboidratos (RUSSEL et al., 1992; SNIFFEN et al., 1992), associando-se a taxa de digestão e a velocidade de passagem da dieta, proporcionando adequado crescimento microbiano, independentemente do nível de proteína utilizado no trabalho.

O GMD verificado para os bezerros no presente experimento foi superior aos relatados por diversos autores para bezerros mantidos ao pé da vaca em condição de campo nativo (COSTA et al., 1981; MOOJEN et al., 1994; RESTLE et al.,1994; e BECKER et al., 1995), bem como para bezerros desmamados precocemente e mantidos exclusivamente em diferentes pastagens cultivadas (MOOJEN et al., 1994; MUEHLMANN et al., 1997; RESTLE et al., 1999). Isto sugere que os níveis de proteína bruta utilizados no presente trabalho propiciaram adequado desenvolvimento ao bezerro desmamado precocemente.

Foi observada tendência linear e negativa para conversão alimentar, com o aumento de $\mathrm{PB}$ na dieta, variando de 4,51 a 3,98 ( $\mathrm{P}=0,0606)$. Melhores valores de conversão alimentar com aumento do nível protéico na dieta também foram encontrados por THOMAS et al. (1976), NEVILLE JR. et al. (1977) e VEIRA et al. (1980). A conversão alimentar é dada pelo quociente entre o CMS e o GMD, refletindo a eficiência com que o alimento é transformado em peso vivo. Dessa forma, os resultados do presente trabalho sugerem que a tendência de melhor conversão alimentar para as dietas com maior teor protéico pode ser explicada pela melhor digestibilidade da dietae, embora não-significativo, pelo maior GMD. Segundo VEIRA et al. (1980), aumentos no nível protéico da dieta proporcionaram melhor digestibilidade da MS, da FDA e do amido, além de maior retenção de nitrogênio pelo animal.

THOMAS et al. (1976) observaram que a equação de regressão relacionando nível de proteína bruta e consumo de matéria seca com o ganho de peso diário foram diferentes, conforme evoluiu o período experimental; citam que proteína bruta e consumo foram igualmente importantes na fase de 41 a 72 dias. Após os 72 dias, o consumo de matéria seca foi muito mais importante que a percentagem de proteína na dieta. Dessa forma, torna-se interessante buscar o rápido desenvolvimento dos compartimentos gastrintestinais, já que o bezerro passa a consumir unicamente alimentos sólidos, ainda que seja conhecido que a quantidade de leite e a qualidade da pastagem influem no desenvolvimento dos compartimentos estomacais ainda na fase pré-desmame (BOGGS et al., 1980; LUSBY et al., 1981).

A Tabela 4 apresenta a evolução do consumo de MS e FDN, como média para todos os tratamentos, com o avanço do período experimental. Não foi verificada interação significativa entre tratamento e período. Observou-se resposta linear e positiva $(\mathrm{P}<0,02)$ para CMS, CMSP, CMSM, CFDN e CFDNP, com o decorrer do período experimental (quatro períodos de 21 dias cada).

De acordo com VALADARES et al. (1997), o consumo eleva com o aumento do peso vivo. Dessa forma, quando comparados o CMS com a evolução do período experimental, observa-se aumento de $63 \%$ no consumo dos animais nos períodos de 1 a 4 , o que proporcionou consumos de 349, 424, 504 e $570 \mathrm{~g} /$ dia de PB para os quatro períodos avaliados, respectivamente. No entanto, o consumo pode ser mais bem expresso em relação ao peso do animal, encontrando-se valores para CMSP e CMSM de 2,31 a 2,66 kg/diae 71,95 a 90,14 g/PV ${ }^{0,75}$, respectivamente, para os períodos 1 e 4 , representando aumentos de $14,7 \%$ para CMSP e $23,1 \%$ para CMSM.

Segundo MERTENS (1992) e VAN SOEST (1994), o consumo de FDN é o que melhor representa a capacidade de consumo para dietas à base de volumosos ou na mistura destes com médias a baixas quantidades de concentrado, pois são os constituintes 
da parede celular que ocupam maior espaço no rúmen. Assim, o CFDN variou de $0,890 \mathrm{~g}$, no período 1, a $1,448 \mathrm{~g}$ no período 4 . Quando o CFDN foi relacionado com o peso vivo, observaram-se aumentos de $12,1 \%$ no CFDNP, variando de 0,973 a 1,090 kg/dia.

Menores CMS de bezerros recém chegados ao confinamento foram também verificados por FLUHARTY et al. (1995), os quais sugeriram, para se obterem altos ganhos de peso nesta fase, elevado nível de PB na dieta para que o baixo consumo não limite o aporte deste nutriente, pois não só o requerimento deve ser atendido, como também os efeitos de estresse pelo manejo devem ser computados.

Os resultados de desempenho obtidos neste trabalho foram comparados com as equações de predição de ganho de peso sugeridas pelo NATIONAL RESEARCH COUNCIL - NRC (1984), como mostra a Tabela 5. Pode-se observar que o NRC (1984) preconiza consumos de 397 e $730 \mathrm{~g} /$ dia de PB para o menor e o maior ganho obtido, respectivamente. No entanto, os consumos de PB diários observados superaram aqueles valores sugeridos pelo NRC (1984), exceto para a dieta com $13 \%$ de PB. No entanto, observa-se que, à medida que se elevou o nível de PB na dieta, aumentou a diferença entre o consumo de PB observado e o preconizado, variando de -25 até $+121 \mathrm{~g} / \mathrm{dia}$ para os tratamentos 13 a $19 \%$ de $\mathrm{PB}$, respectivamente.

Da mesma forma que para $\mathrm{PB}$, os valores de energia líquida de ganho (Elg) preconizado variaram de 1,181 a 1,396 Mcal/dia para os tratamentos 13 a $19 \%$ de PB, respectivamente. Nenhum dos tratamentos alcançou os consumos de Elg sugeridos, observando, como maior valor, $1,083 \mathrm{Mcal} / \mathrm{dia}$ para o tratamento $15 \%$ de PB. Era de se supor que o maior consumo de Elg fosse para o tratamento $19 \%$, que apresentou o maior GMD. Entretanto, o tratamento com $15 \%$ de PB apresentou maior CMS $(2,95 \mathrm{~kg})$, refletindo no maior consumo de energia.

Vários autores citam divergências entre os consumos de energia e proteína observados e os indicados pelo NRC (1984). PASCOAL (1992), trabalhando com novilhos de 3,5 anos de idade, verificou que Elg preconizada pelo NRC (1984) foi muito superior ao consumo de Elg observado, sugerindo que esta diferença poderia estar relacionada à categoria animal utilizada. Entretanto, ao revisar diversos experimentos em confinamento, o mesmo autor observou que estas diferenças entre Elg consumida e preconizada também se aplicam a outras categorias.

Consta da Tabela 5 o balanço de energia líquida de ganho (BElg) e de proteína bruta (BPB), obtido pela diferença entre o consumo observado e o preconizado. Pode ser observado no BPB que, com exceção do nível 13\% de PB, houve consumos de PB acima dos recomendados pelo NRC (1984) para os ganhos de peso obtidos, sendo que a diferença aumentou,

Tabela 4 - Evolução e equação de regressão para consumo médio diário de matéria seca (CMS), por $100 \mathrm{~kg}$ de peso vivo (CMSP) e tamanho metabólico (CMSM), consumo médio diário de FDN (CFDN), por $100 \mathrm{~kg}$ de peso vivo (CFDNP), ganho de peso médio diário (GMD) e conversão alimentar (CA), de acordo com o avanço do período experimental de bezerros de corte alimentados com diferentes níveis de proteína

Table 4 - Evolution and regression equation of daily dry matter intake (DMI), per $100 \mathrm{~kg}$ of live weight (DMIP) and metabolic weight (DMIM), average daily NDF intake (NDFI), per $100 \mathrm{~kg}$ of live weight (NDFIP), average daily gain (ADG) and feed:gain ratio (F/G), according to the experimental period of beef calves fed different protein levels

\begin{tabular}{|c|c|c|c|c|c|}
\hline \multirow[t]{2}{*}{ Item } & \multicolumn{4}{|c|}{$\begin{array}{l}\text { Período } \\
\text { Period }\end{array}$} & \multirow[t]{2}{*}{$\begin{array}{l}\text { Equação de regressão } \\
\text { Regression equation }\end{array}$} \\
\hline & 1 & 2 & 3 & 4 & \\
\hline $\begin{array}{l}\text { CMS, } \mathrm{kg} \\
D M I, k g\end{array}$ & $2,18^{\mathrm{d} 1}$ & $2,65^{\mathrm{c}}$ & $3,15^{\mathrm{b}}$ & $3,56^{\mathrm{a}}$ & $\begin{array}{l}\mathrm{CMS}=1,7297+0,4625 \mathrm{P} \\
D M I\end{array}$ \\
\hline $\begin{array}{l}\text { CMSP, } \mathrm{kg} \\
D M I P, \mathrm{~kg}\end{array}$ & $2,32^{\mathrm{c}}$ & $2,46^{\mathrm{b}}$ & $2,66^{\mathrm{a}}$ & $2,66^{\mathrm{a}}$ & $\begin{array}{l}\text { CMSP }=2,2990+0,1004 \mathrm{P} \\
D M I P\end{array}$ \\
\hline $\begin{array}{l}\text { CMSM, g/PV } 0,75 \\
D M I M, g / L W \cdot 75\end{array}$ & $73,40^{\mathrm{c}}$ & $80,54^{b}$ & $87,76^{\mathrm{a}}$ & $90,32^{a}$ & $\begin{array}{l}\text { CMSM=68,508+5,80P } \\
\text { DMIM }\end{array}$ \\
\hline $\begin{array}{l}\text { CFDN, } \mathrm{kg} \\
\mathrm{NDFI}, \mathrm{kg}\end{array}$ & $0,890^{\mathrm{d}}$ & $1,081^{\mathrm{c}}$ & $1,283^{b}$ & $1,448^{\mathrm{a}}$ & $\begin{array}{l}\mathrm{CFDN}=0,678+0,1688 \mathrm{P} \\
N D F I\end{array}$ \\
\hline $\begin{array}{l}\text { CFDNP, } \mathrm{kg} \\
I N D F P, \mathrm{~kg}\end{array}$ & $0,973^{\mathrm{c}}$ & $1,031^{\mathrm{c}}$ & $1,092^{b}$ & $1,090^{\mathrm{a}}$ & $\begin{array}{l}\mathrm{CFDNP}=0,9256+0,0422 \mathrm{P} \\
N D F I P\end{array}$ \\
\hline
\end{tabular}

${ }^{1}$ Médias na mesma linha seguidas de letras diferentes diferem $(\mathrm{P}<0,03)$.

${ }_{1}^{1}$ Means in the same row followed by different letters differ $(P<.03)$.

$\mathrm{P}=1 ; 2 ; 3 ; 4$ períodos de 21 dias (periods of 21 days). 
à medida que se elevou o nível protéico da dieta. $\mathrm{O}$ BElg foi negativo para todos os tratamentos, aumentando a diferença no sentido das dietas com maior concentração de PB. Esta situação sugere que, para obter acréscimos no GMD, o nível energético das dietas deve ser aumentado.

Os resultados obtidos, principalmente em relação ao ganho de peso dos bezerros, mostram que a recomendação que é direcionada para produtores que empregam a técnica de desmame precoce deve ser revista, no que diz respeito ao nível de proteína na dieta para bezerros. Elevar o nível protéico sem obter respostas no ganho de peso torna o sistema menos eficiente economicamente, já que a proteína é considerada um dos componentes que mais oneram o custo da dieta (RUSSEL, 1992).

Tabela 5 - Estimativas do consumo de energia líquida de mantença (Elm, Mcal/dia), energia líquida de ganho (Elg, Mcal/dia) e proteína bruta (PB, g/dia), dos balanços de Elg (BElg, Mcal/dia) e do balanço de PB (BPB, g/dia), comparadas com as exigências sugeridas pelo NRC (1984) para os ganhos de peso obtidos (GMD, kg/dia)

Table 5 - Estimates for net energy intake for maintenance (NEm, Mcal/day), net energy for gain (NEg, Mcal/day), crude protein intake (CP, g/day), NEg balance (BNEg, Mcal/ day) and crude protein balance (BCP, g/day), compared to the requirements predicted by the NRC (1984) for the obtained weight gains (ADG, $\mathrm{kg} / \mathrm{dia}$ )

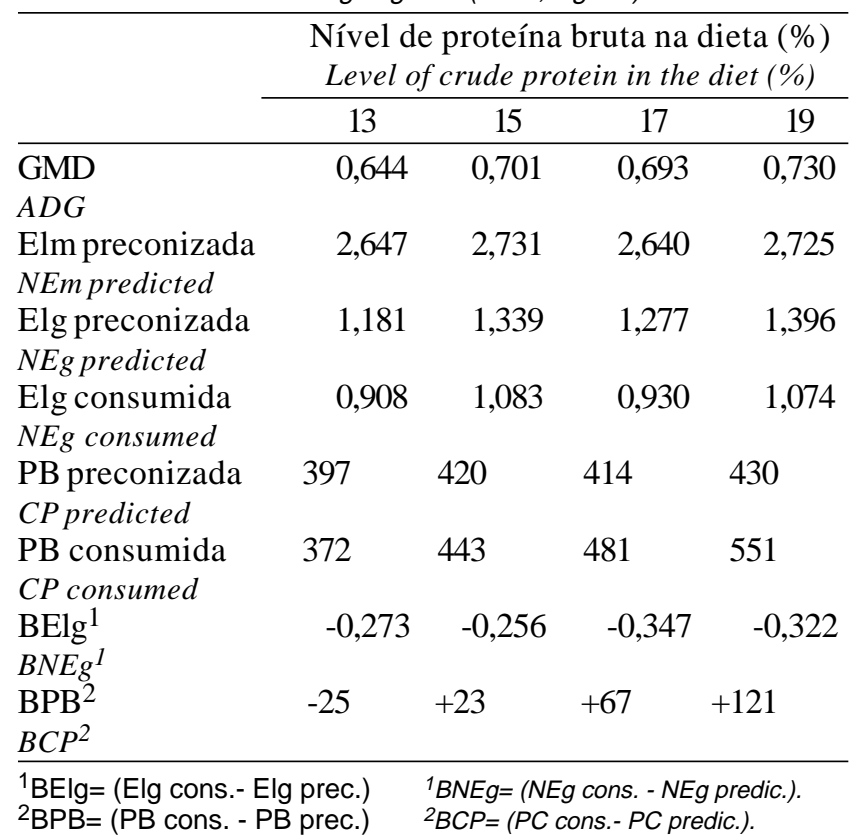

\section{Conclusões}

Para o nível de energia utilizado, não há benefício no ganho de peso de bezerros de corte desmamados precocemente, quando o nível de proteína é elevado de 13 para $19 \%$. O nível de PB não influenciou os consumos de matéria seca (CMS, CMSP e CMSM) e de FDN (CFDN e CFDNP).

O consumo de MS, assim como de FDN, nas suas diferentes formas de expressão, aumentou linearmente com o avanço no período experimental, demonstrando o aumento da capacidade ingestiva dos bezerros.

\section{Referências Bibliográficas}

BECKER, A.S, HILLEBRAND, G.L., POLLI, V.A. et al. 1995. Desempenho de fêmeas "threecross" e Hereford. III. Características com o terneiro. Pesq. Agropec. Gaúcha, 1(1):103-109.

BOGGS, D.L., SMITH, E.F., SCHALLES, R.R. et al. 1980 Effects of milk and forage intake on calf performance. J. Anim. Sci., 51(3):550-553.

COSTA, A.M., RESTLE, J., MÜLLER, L. 1981. Influência da pastagem cultivada no desempenho reprodutivo de vacas com cria ao pé. Rev. Centro de Ciências Rurais, 11(4):187-200.

FLUHARTY, F.L., LOERCH, S.C. 1995. Effects of protein concentration and protein source on performance of newly arrived feedlot calves. J. Anim. Sci., 73(5):1585-1594.

JAHN, E., CHANDLER, P.T. 1976. Performance and nutrient requirements of calves fed varying percentages of protein and fiber. J. Anim. Sci., 42(3):724-735.

JUNG, H.G., ALLEN M.S. 1995. Characteristics of cell wall affecting intake and digestibility of forages by ruminants. $J$. Anim. Sci., 73(5):2774-2790.

LUSBY, K.S., WATTEMANN, R.P., TURMAN, E.J. 1981. Effects of early weaning calves from first-calf heifers on calf and heifer performance. J. Anim. Sci., 53(5):1193-1197.

MERTENS, D.R. Análise de fibras em alimentos e seu uso na avaliação e formulação de rações. In: SIMPÓSIO INTERNACIONAL DE RUMINANTES, 1992, Lavras, MG. Anais... Lavras, 1992, 381p.

MOOJEN, J.G., RESTLE, J., MOOJEN, E.L. 1994. Efeito da época de desmama e da pastagem no desempenho de vacas e terneiros de corte. 1. Desempenho dos terneiros. Ciência Rural, 24(12):399-403.

MUHELMANN, L.D., ROCHA, M.G., RESTLE, J. 1997. Utilização de pastagens de estação quente com bovinos desmamados precocemente. R. Bras. Zootec., 26(3):384-389.

NEVILLE JR, W.E., McCORMICK, W.C. 1981. Performance of early- and normal- weaned beef calves and their dams. $J$. Anim. Sci., 52(4):715-724.

NEVILLE JR.,W.E., HELLWIG, R.E., RITTER III, R.J et al. 1977. Effect of diet protein level on weight gains of early weaned beef calves. J. Anim. Sci., 44(4):687-693.

NATIONAL RESEARCH COUNCIL - NRC. 1984. Nutrient requirement of beef cattle. 6.ed., Washington, DC. 50p.

OWENS, F.N., GOETSCH, A.L. 1993. Fermentación ruminal. In: CHURCH, D.C. El ruminante, fisiología digestiva $y$ nutrición. Zaragoza, España: Ed. Acríbia. p.159-190. 
PASCOAL, L.L. Efeito da proteína de alta e de baixa degradabilidade ruminal associada à cana-de-açúcar ou ao capim napier na alimentação de bovinos confinados. Santa Maria, RS: UFSM, 1992. 159p. Dissertação (Mestrado em Zootecnia) - Universidade Federal de Santa Maria, 1992.

PASCOAL, L.L., VAZ, F.N. 1996. Desmame precoce aos sessenta dias. In: RESTLE, J., BRONDANI, I.L., PASCOAL, L.L. et al. Técnicas avançadas na recria e engorda de bovinos de corte. Santa Maria, RS. p.35-46.

PETERSON, G.A., TURNER, T.B., IRVIN, K.M. et al. 1987. Cow and calf performance and economic considerations of early weaning of fall-born beef calves. J. Anim. Sci., 64:15-22.

RESENDE, F.D, QUEIROZ, A.C., FONTES, C.A.A. et al. 1995. Fibra em detergente neutro versus fibra em detergente ácido na formulação de dietas para ruminantes. R. Bras. Zootec., 24(3):342-350.

RESTlE, J., DALlA PORTA, M.A., SENNA, D.B. et al. Desempenho reprodutivo de novilhas de diferentes grupos genéticos submetidas previamente a duas idades de desmame. In: REUNIÃO ANUAL DA SOCIEDADE BRASILEIRA DE ZOOTECNIA, 29, Lavras, 1992. Anais... Lavras, 1992, p.219.

RESTLE, J., GRASSI, C., FEIJÓ, G.L.D. 1994. Evolução do peso de bovinos de corte inteiros ou castrados em diferentes idades. Pesq. Agropec. Bras., 29(10):1631-1635.

RESTLE, J., VAZ, F.N. Desmame precoce de bezerros. In: SIMPÓSIO INTERNACIONAL SOBRE PRODUÇÃO INTENSIVA DE GADO DE CORTE, 2, São Paulo, SP, 1998. Anais... São Paulo, p.3-9, 1998.

RESTLE, J, POLLI, V.A, ALVES FILHO, D.C. et al. 1999. Desenvolvimento de bovinos de corte de diferentes grupos genéticos desmamados aos três ou sete meses. Rev. bras. zootec., 28(1):1023-1030.

ROBISON, O.W., YUSUFF, M.K.M., DILLARD, E.U. 1978. Milk production in Hereford cows. I. Means and correlations. J. Anim. Sci., 47(1):131-136.
RUSSEL, J.B. Minimização de perdas de nitrogênio pelos ruminantes. In: SIMPÓSIO INTERNACIONAL DE RUMINANTES, Lavras, MG. Anais... Lavras, p.232-252, 1992.

RUTLEDGE, J.J., ROBISON, O.W., AHLSCHWEDE, W.T. et al. 1971. Milk yield and its influence on 205-day weight of beef calves. J. Anim. Sci., 33(3):563-567.

STATICAL USER'S GUIDE/SAS. 1990. Version 6.0, 4.ed, v.1. SAS Institute Inc., Cary, NC, USA. February. 890p.

SNIFFEN, C.J., O'CONNOR, J.D., VAN SOEST, P.J. et al. 1992. A Net Carbohydrate and Protein System for Evaluating Cattle Diets: II. Carbohydrate and protein availability. $J$. Anim. Sci., 70(9):3562-3577.

THOMAS, J.W., TINNIMIT, P. 1976. Amounts and sources of protein for dairy calves. J. Dairy Sci., 59(4):1967-1985.

VAN SOEST, P.J. 1994. Nutritional ecology of the ruminant. 2.ed. Ithaca. $476 \mathrm{p}$.

VALADARES, R.F.D., GONÇALVES, L.C., RODRIGUES, N.M. et al. 1997. Níveis de proteína em dietas de bovinos. 1 . Consumo e digestibilidades aparentes totais e parciais. $R$. Bras. Zootec., 26 (6):1252-1258.

VEIRA, D.M., MACLEOD, G.M., BURTON, J.H. et al. 1980. Nutrition of the weaned Holstein calf. II. Effects of dietary protein level on nitrogen balance, digestibility and feed intake. J. Anim. Sci., 50(5):945-951.

Recebido em: 03/08/99

Aceito em: 13/04/00 